\title{
Experiences of Jamaican men who have undergone no-scalpel vasectomy at the University of the West Indies
}

This article was published in the following Dove Press journal:

Open Access Journal of Contraception

12 October 2010

Number of times this article has been viewed

\author{
Vernon DaCosta' \\ Tenaj Lewis' \\ Sean Wynter' \\ Loxley Christie' \\ John Harriott ${ }^{1}$ \\ Joseph Frederick' \\ Marvin Reid ${ }^{2}$ \\ 'University Hospital of the West \\ Indies, Mona, Kingston, Jamaica; \\ ${ }^{2}$ University of the West Indies, \\ Tropical Medicine Research Institute, \\ Mona, Kingston, Jamaica
}

Correspondence: Vernon Eric DaCosta Hugh Wynter Fertility Management Unit, University of the West Indies, Mona,

Kingston 7, Jamaica

Tel +876 8550434

Email vedIII@hotmail.com
Objective: The objective of this study was to assess the satisfaction and morbidity associated with no-scalpel vasectomy (NSV) of men at the University of the West Indies (UWI) as well as to determine whether preoperative counseling modulated the reported NSV experience.

Methods: A 10-year retrospective cohort study of men undergoing NSV at Hugh Wynter Fertility Management Unit (HWFMU) of the University of the West Indies from January 1, 1999 to December 31, 2008. The demographics of the patients, complications of the procedure, and postoperative follow-up were assessed. Patient satisfaction with the procedure was assessed by a questionnaire.

Results: During this period, 82 NSVs were performed. Approximately, $91 \%$ of the men are married, $7 \%$ single, and $2 \%$ divorced. The mean $( \pm \mathrm{SD})$ age of the clients was $39 \pm 5.8$ years, the procedure was done after siring three (median) children $(\min =0, \max =7)$ and $3.3 \pm 3.8$ years after the last child was born. Ninety-two percent (92.6\%) reported the experience as good and not associated with any significant pain. There was one failure $(1.21 \%)$ but there were no pregnancies resulting from this case. Follow-up to date has indicated that $96.3 \%$ of patients interviewed would recommend this procedure and have no regrets.

Conclusion: The complication rate in this study was very low. The experiences of more than $98 \%$ of gentlemen who underwent NSV were overwhelmingly positive. Most men reported an improved libido with only a single gentleman regretting his procedure.

Keywords: no scalpel vasectomy, Jamaican men, experiences

\section{Introduction}

Vasectomy is a simple, safe, effective, and inexpensive method of permanent contraception for men. ${ }^{1,2}$ The no-scalpel vasectomy (NSV), a technique developed in China by Dr Shungiang Li in 1974 and used in other countries since 1986, ${ }^{1}$ was first performed at the Hugh Wynter Fertility Management Unit (HWFMU) in 1996.

The main reported surgical complications of NSVs were; scrotal hematoma, wound infection, scrotal sinus, vasectomy failure, and sperm granuloma. Scrotal hematoma accounted for approximately $0.3 \%-17 \%$, infections $0.15 \%-7.1 \%$, scrotal sinus $0.32 \%$, vasectomy failure $0.01 \%-4.2 \%$, and sperm granuloma $0.005 \%-4.3 \%$. $^{3-5}$

NSV offers several advantages over conventional vasectomy: fewer complications, less pain during the procedure and early follow-up periods, and earlier resumption of sexual activity after surgery. ${ }^{6-8}$ Although NSV is more economical and has less associated morbidity than the female surgical sterilization methods, only 60 million vasectomies have been carried out worldwide in comparison to 140 million tubal ligations. ${ }^{2}$ This difference in proportion is likely to be due to 
sociocultural differences as well as to lack of awareness among health care professionals and men about the morbidity (safety) of NSV.

We therefore undertook this study to assess the morbidity as well as the satisfaction of men who had undergone the procedure at the HWFMU of the University of the West Indies. A secondary objective was to determine whether preoperative counseling modulated the reported NSV experience.

\section{Methods}

Eighty-two men who had NSV procedure from 1998 to 2008 at the HWFMU of the University of the West Indies were eligible for the study. Sociodemographic information such as their age, professions, marital status, number of children sired prior to the procedure, and the year of the procedure were extracted from their medical records. A sample of these men $(\mathrm{N}=27)$ was contacted via telephone and asked to consent and take part in a confidential, questionnaire that consisted of 26 questions that queried their experiences preoperatively, intraoperatively, and postoperatively.

This study was approved by the Faculty of Medical Sciences Ethics Committee, University of the West Indies.

\section{Statistics}

Values are expressed as counts, median with minimum and maximums or means $\pm \mathrm{SD}$ as appropriate. To determine whether preoperative counseling modulated the reported experience with NSV, the sample of men who were interviewed were dichotomized into two groups, a group that received preoperative counseling and a group of men who did not receive preoperative counseling. Differences in continuous outcome variables were determined by the Mann-Whitney rank test or independent $t$-test as appropriate and associations between categorical outcome variables and counseling groups were assessed using the chi square statistics. A $P$ value $\leq 0.05$ was considered significant. Stata for Windows (version 10; Stata Corp, College Station, Tx) was used for statistical analyses.

\section{Results}

Eighty-two men were eligible for enrollment in the study. Twenty-seven of these men completed the interviewer-administered questionnaire. There was no difference in the mean age of persons interviewed compared with the mean age of the source sample $(P=0.38)$ (Table 1). Additionally there was no difference in proportion of men who were married, or the proportion with tertiary level education or the median number of children sired in the sample of men interviewed compared with all men.

Only one of the 82 men in the source sample had never sired a child and chose vasectomy as his primary means of contraceptive. Thirty-five percent $(n=29)$ had two children, $35.4 \%$ had sired three children, $13.4 \%(n=11)$ sired four children, $6.1 \%$ sired six children $(n=5), 5.1 \%$ had sired only a single child $(n=4)$, and two men had fathered seven children. Ninety-one percent of men who had undergone a vasectomy had two or more children previously.

The mean duration of the procedure was $23.8 \pm$ 14.0 minutes. Postoperative complications comprised small hematomas in $1.21 \%$, sperm granuloma was seen in $4.3 \%$ of cases $(n=4)$, and there was one failure $(1.21 \%)$ as evidenced by postoperative semen analysis but there were no pregnancies resulting from this case.

Of the 27 men who completed the questionnaire to determine the effect of preoperative counseling on level of satisfaction with the procedure, 15 received counseling and 12 did not receive counseling. Patients, who reported no preoperative counseling thought the preoperative counseling was unnecessary, since they had done extensive research of the procedure online. One man who reported inadequate counseling had his procedure reversed and has subsequently sired one child. There were no differences in the sociodemographic characteristics of the group of men who received counseling compared with those who did not (Table 2).

On a pain scale of $0-10$ ( 0 corresponding to no pain and 10 the worst pain ever experienced) the men were asked to quantify the amount of pain they felt on resting at home after the procedure, during normal physical activity and then

Table I Comparison of interviewed sample with all men who had vasectomy

\begin{tabular}{llll}
\hline Variable & All men & Interviewed sample & P value \\
\hline Age $^{\mathrm{a}}$ & $39.3 \pm 6.1(29-66)$ & $40.4 \pm 5.6(28-5 \mathrm{I})$ & 0.37 \\
Marital status $^{\mathrm{b}}$ & $76(93 \%)$ & $25(93 \%)$ & 1.0 \\
Tertiary level education & $66(80 \%)$ & $26(96 \%)$ & 0.067 \\
Number of children siredc & $3(0-7)$ & $3(1-6)$ & 0.5 \\
\hline
\end{tabular}

Notes: ${ }^{a}$ Values are mean \pm standard deviation ( $\min$ and $\left.\max \right)$; ${ }^{b}$ values are count $(\%)$; ${ }^{c}$ values are median $(\min$ and $\max )$. 
Table 2 Sociodemographic and reported experience in men who completed questionnaire

\begin{tabular}{|c|c|c|c|c|}
\hline Variables & $\begin{array}{l}\text { All men } \\
(n=27)\end{array}$ & $\begin{array}{l}\text { No prior counseling } \\
(n=I 2)\end{array}$ & $\begin{array}{l}\text { Prior counseling } \\
(n=15)\end{array}$ & $P$ value \\
\hline Age at procedure ${ }^{a}$ & $40.4 \pm 5.6$ & $40.1 \pm 5.7$ & $40.8 \pm 5.6$ & 0.7 \\
\hline Age now ${ }^{\mathrm{a}}$ & $46.9 \pm 6.9$ & $47.1 \pm 7.5$ & $46.5 \pm 6.3$ & 0.8 \\
\hline Married & 25 & II & 14 & 0.9 \\
\hline Tertiary level education & 26 & 12 & 14 & 0.4 \\
\hline Children sired ${ }^{\mathrm{b}}$ & $3(1,6)$ & $3(1,5)$ & $3(2,6)$ & 0.6 \\
\hline Rating of experience & & & & 0.4 \\
\hline Excellent & 4 & 3 & 1 & \\
\hline Good & 22 & 11 & 11 & \\
\hline Poor & 1 & I & 0 & \\
\hline Rest pain ${ }^{b}$ & $2(0,5)$ & $2(0,5)$ & $2(0,4)$ & 0.9 \\
\hline Pain on activity ${ }^{b}$ & $0(0,4)$ & $0(0,4)$ & $0(0,3)$ & 0.4 \\
\hline Days of analgesia ${ }^{\mathrm{b}}$ & I $(0,7)$ & $0(0,6)$ & $2(0,7)$ & $<0.03$ \\
\hline Sex by day 3 & 10 & 6 & 4 & 0.7 \\
\hline Sex by day 7 & 18 & 13 & 8 & 0.2 \\
\hline Source of information & & & & 0.7 \\
\hline Friend & 8 & 5 & 3 & \\
\hline Medical doctor & 7 & 4 & 3 & \\
\hline Read about & 11 & 6 & 5 & \\
\hline Other & 1 & 0 & 1 & \\
\hline Libido unchanged & 19 & 11 & 8 & 0.5 \\
\hline Sexual performance unchanged & 16 & 9 & 7 & 1 \\
\hline No regrets & 26 & 12 & 14 & 0.7 \\
\hline
\end{tabular}

Notes: Values are counts: ${ }^{2}$ values are mean \pm standard deviation; ${ }^{b}$ values are medians with minimum and maximum $P$ value comparing group who received no preoperative counseling with group that received preoperative counseling.

during sexual intercourse. At rest none of the men reported a pain score greater than 5 . On commencement of normal physical activity none of the men reported a pain score greater than 4 and none of the men reported having pain during sexual intercourse. There was no difference in the median pain score in the men who received preoperative counseling compared to those who did not. Nevertheless, thirteen $(48.1 \%)$ men reported using analgesics, which were prescribed after the procedure while fourteen $(51.9 \%)$ men reported not taking any analgesics after their procedure. Further men who received preoperative counseling required significantly more days of analgesia than those without. Only two patients reported significant swelling and pain (score of 5) after the procedure requiring an emergency doctor's visit outside of routine follow up.

Most men had not returned to normal sexual activity by day 3 post-vasectomy. Only ten men (37\%) felt comfortable enough for routine sexual activity before day 3 . However, by day 7 post-procedure, twenty-one men $(77.8 \%)$ had resumed normal sexual activity and 100\% had resumed normal sexual activity by day 14 . Nineteen men (70.4\%) who responded to the questionnaire reported that there was no change in the desire for sexual intercourse. Additionally $59.3 \%$ reported that their performance was unchanged. There were no differences between the men who received prior counseling compared with those who did not in days for resumption of sexual activity, libido, and sexual performance.

Four $(15 \%)$ of the men who responded to the questionnaire reported their experiences as excellent and pain free. Twenty-one men (77.8\%) reported the experience as good and not associated with any significant pain and $7.4 \%$ reported having a poor experience due to inadequate analgesia. One man reported being uncomfortable, since he was unprepared for the presence of women in the operating room. Twenty-four (89\%) of interviewed men reported having chosen vasectomy because their families were complete. Three men (11\%) reported that their wives had had difficult pregnancies and that a subsequent pregnancy was thought to be harmful. None of the men reported a personal health problem as a reason for choosing vasectomy. Seventy-four percent $(74.5 \%)$ of the men who had chosen vasectomies were the ones in the relationship who primarily took responsibility for family planning prior to the vasectomy, whether by choosing to wear condoms or practicing withdrawal methods. Twenty-six men (96.3\%) would recommend this procedure and had no regrets while $(3.7 \%)$ regretted the procedure, reporting he would not recommend vasectomies and has had his vasectomy reversed. 


\section{Discussion}

This study sought to report on the satisfaction and morbidity associated with NSV in Jamaican men and whether preprocedure counseling modulated the reported experience. In keeping with other studies, the frequencies of postoperative complications were low consisting of small hematomas in $1.2 \%$, and sperm granuloma in $4.3 \%$ of cases. The majority of men, $92.6 \%$, reported the experience as good and not associated with any significant pain, with $96 \%$ of men reporting that they had no regrets and would recommend the procedure. There was one failure (1.21\%) but there were no pregnancies resulting from this case. Preoperative counseling was not associated with level of satisfaction in this study.

There are many reasons why vasectomy is not a popular contraceptive option in Jamaica and these include: large numbers of impermanent relationships, ${ }^{9}$ having children is seen as an example of male potency, ${ }^{10}$ significant misconceptions regarding vasectomy still exist, and most importantly bias advice from providers. For example, a 1994 survey of physicians in Jamaica found that $80 \%$ advocated female sterilization for limiting childbearing, with another $11 \%$ advocating injectables, and $9 \%$ advising other methods. Vasectomy was never ever mentioned in this "well-designed" survey. ${ }^{9}$ Provider bias was also demonstrated by Erviti et al. ${ }^{11}$

Extensive research indicated that vasectomy is not associated with an increased risk of testicular cancer, prostate cancer, or myocardial infarction. ${ }^{12,13}$ These factors may be a significant barrier to acceptability by Jamaican men and will have to be overcome with education. It is therefore; not surprising that over $80 \%$ of our patients had tertiary education and had done research on the procedures prior to undergoing vasectomies. It would appear that a lack of tertiary education may be a barrier to voluntary male contraception. These findings are similar to those of Barone et al. ${ }^{14}$

The effect of preoperative counseling was assessed in the sample of men who completed the questionnaire as has been reported that competent counseling is essential to success. ${ }^{15,16}$ From our study only $44.4 \%$ of men reported having received counseling prior to vasectomy of which only $55.6 \%$ thought the counseling was adequate. Of the men who thought the counseling was adequate they all reported that they thought the material was redundant in comparison to the information available in the media such as online and recent news articles. Dialectic counseling appears important in relieving apprehension but didactic counseling does not appear to be necessary and possible written material may be adequate.

In previous studies, the strongest predictor for wanting a vasectomy reversal is an age younger than 30 years at the time of the procedure. ${ }^{16}$ Our client who had regretted and reversed his procedure was 35 years old at the time of vasectomy and had completed his family. He, however, later divorced and remarried his second wife who had no children of her own. Most men in our study 91\% were married; the others were divorced or single. Only one man had never fathered a child $(1.4 \%)$ while greater than $98 \%$ of men had sired children. Therefore, an ideal candidate for vasectomy appears to be a man, middle aged, having sired at least two children in a stable, secure union, and having achieved a tertiary level of education.

While more than $96 \%$ of our interviewed patients had recommended this procedure, they themselves had no regrets. Only $25.9 \%$ had the procedure recommended by a medical professional reflecting yet another barrier in voluntary male sterilization, that being the medical profession. Almost thirty percent $(29.6 \%$ ) of our men had the procedure recommended to them by a colleague while $96 \%$ of our men would happily recommend the procedure to their colleagues.

Complications of the NSV in the study found that $51.9 \%$ required analgesic post procedure, while $48.1 \%$ required no analgesics. The mean duration of analgesic use was 1.5 days. Eighty-eight (88.9\%) percent of our patients had returned to normal physical activity by day 3 post-procedure while $100 \%$ return to normal physical activity by day 7 . Return to normal sexual activity was $37 \%$ by day $3,77 \%$ by day 7 , and $100 \%$ return to sexual intercourse by day 14 . None of the interviewed patients had a pain score greater than $5 / 10$ on the day of the procedure and none of the interviewed patients had a pain score greater than $4 / 10$ the day after. On commencing sexual intercourse none of the interviewed men experienced any pain. Fifty-one percent of interviewed patients required over the counter drugs and the mean duration of medication was two days. Only two gentlemen required an emergency doctor's consultation and this is in keeping with acceptable complication rates..$^{3-5}$

The results have provided a more detailed representation of the local data, which can be presented to the patients (verbally or written) that will allow the patients to have a better expectation of the postoperative course. Detailed information decreases unrealistic expectations and improves post procedure experiences.

The interviewed men reported that libido was unchanged in $70.4 \%$, and improved in $25.9 \%$. Two gentlemen reported premature ejaculation and increased ejaculates as causes of worsening sexual performance. However, 59.3\% claimed that performance had not changed and $33.3 \%$ described performance as better than before the procedure claiming that 
confidence and spontaneity had improved their performance. These findings are similar to those of Smith et al. ${ }^{17}$

Our study has a number of limitations including a small sample size, the recall time was too long for some of the men, and only $33 \%$ responded to the questionnaire.

In conclusion, the experiences of more than $98 \%$ of men having undergone a NSV are overwhelmingly positive. With only a single client regretting his procedure and having had the procedure reversed. This family planning method has great significance in the developing world where unwanted pregnancies still remain high. Campaigns that are geared towards this method will have to include these specific positive experiences that men may not want to discuss in person. We believe that more Jamaican men would choose NSV as a means of limiting the number of children that they can potentially sire if they were informed of the easy availability, relatively low cost, positive personal experiences, very low failure rates, and the very high safety that was associated with this procedure.

Preoperative counseling did not seem to alter the reported NSV experience in this study. However, further studies are needed to determine the optimum method of preparing men for their vasectomy experience.

\section{Disclosure}

There is no known competing interest by any of the authors participating in this study.

\section{References}

1. Li SQ, Goldstein M, Zhu J, Huber D. The no-scalpel vasectomy. J Urol. 1991;145(2):341-344.

2. Goldacre MJ, Clarke JA, Heasman MA, Vessey MP. Follow-up of vasectomy using medical record linkage. Am J Epidemiol. 1978;108(3): 176-180.
3. Pant P, Sharma J, Subba S. Scrotal haematoma: The most common complication of no scalpel vasectomy. Kathmandu Univ Med J. 2007;5(2):279-280.

4. Labrecque M, Dufresne C, Barone MA, St-Hilaire K. Vasectomy surgical techniques: a systematic review. BMC Med. 2004;24(2):21.

5. Cook LA, Pun A, van Vliet H, Gallo MF, Lopez LM. Scalpel versus no-scalpel incision for vasectomy. Cochrane Database Syst Rev. 2007; 18(2):CD004112.

6. AVSC International. No-scalpel vasectomy: An illustrated guide for surgeons, 2nd edition. New York, NY: AVSC International; 1997.

7. Sokal D, McMullen S, Gates D, Dominik R. A comparative study of the no scalpel and standard incision approaches to vasectomy in 5 countries. The Male Sterilization Investigator Team. J Urol. 1999;162(5): $1621-1625$.

8. Haws JM. Study shows many US doctors now use NSV. AVSC News. 1998;36(4):3.

9. Bailey W, Clyde M, Smith S, et al. Mapping Study and Private Physicians' Survey Opportunities for Expanded Family Planning Services in Jamaica: Final Report. Kingston, Jamaica: Prepared for; National Family Planning Board; 1994.

10. MacCormack CP, Draper A. Social and cognitive aspects of female sexuality in Jamaica. In Caplan P, editor. The cultural construction of sexuality. London, England: Routledge; 1987:143-165.

11. Erviti J, Sosa Sánchez IA, Castro R. Social origin of contraceptive counseling practices by male doctors in Mexico. Qual Health Res. 2010;20(6):778-787.

12. Herndon N. Making vasectomy attractive. Network. 1992;13(1):28-30.

13. Kalanthakaphan P. Experience and comments on vasectomy operation services in rural area. J Thai Assoc Volunt Steriliz. 1982;1-10.

14. Barone MA, Johnson CH, Luick MA, Teutonico DL, Magnani RJ. Characteristics of men receiving vasectomies in the United States, 1998-1999. Perspect Sex Reprod Health. 2004;36:27-33.

15. Finger WR. Getting more men involved. Network. 1992;13(1):4-6.

16. Dassow P, Bennett J, Finger W. Vasectomy offers many advantages. Network. 1997;18(1):12-15.

17. Smith A, Lyons A, Ferris J, Richters J, Pitts M, Shelley J. Are sexual problems more common in men who have had a vasectomy? A population-based study of Australian men. J Sex Med.2010; 7(2 Pt 1): 736-742.
Open Access Journal of Contraception

\section{Publish your work in this journal}

Open Access Journal of Contraception is an international, peerreviewed, open access, online journal, publishing original research, reports, reviews and commentaries on all areas of contraception. In addition to clinical research, demographics and health-related aspects, the journal welcomes new findings in animal and preclinical studies

\section{Dovepress}

relating to understanding the biological mechanisms and practical development of new contraceptive agents. The manuscript management system is completely online and includes a very quick and fair peer-review system. Visit http://www.dovepress.com/testimonials.php to read real quotes from published authors. 